\title{
Nipple Reconstruction Using a Scar-Based Modified C-V Flap
}

Won Chul Choi ${ }^{1}$, Hyun Gon Choi ${ }^{1}$, Jee Nam Kim ${ }^{1}$, Myung Chul Lee', Dong Hyeok Shin', Soon Heum Kim², Cheol Keun Kim², Dong In Jo ${ }^{2}$

${ }^{1}$ Department of Plastic and Reconstructive Surgery, Konkuk University Medical Center, Konkuk University School of Medicine, Seoul; ${ }^{2}$ Department of Plastic and Reconstructive Surgery, Konkuk University Chungju Hospital, Konkuk University School of Medicine, Chungju, Korea

No potential conflict of interest relevant to this article was reported.
Background Numerous techniques have emerged for nipple-areolar complex (NAC) over the years. Scar-based modified C-V flap technique is a new method for creating NAC, surgeons can accomplish nipple reconstruction and scar revision simultaneously. This article described the modified C-V flap technique for nipple reconstruction. This modified method is simple and reliable with good outcome.

Methods To evaluate the effectiveness of our technique, we reviewed 21 patients who underwent nipple reconstruction using the scar-based modified C-V flap technique. For scar-based modified C-V flap, a C flap was designed to match the contralateral nipple in width while a $V$ flap including scar after mastectomy was designed. The flap pedicle was centrally located. The $V$ flap was then fixed surrounding the central part with a proper shape and volume considering the distal part of the flap that had poor vascularization. Results The average age of the 21 patients was 48.4 years. The average length of follow up was 7.4 months. Complication rate was 19.0\% including projection loss in 2 cases, tip necrosis in 1 case, postoperative infection in 1 case, and wound dehiscence in 1 case. Reoperations were performed for 2 cases of projection loss, 1 case of partial flap necrosis, and 1 case of wound dehiscence.

Conclusions The scar-based modified C-V flap technique is a simple and reliable method for nipple reconstruction with aesthetic outcome. Patients who have undergone this surgical technique tend to have great satisfaction with the results.

Keywords Mammaplasty, Nipples, Reconstructive surgical procedures

\section{INTRODUCTION}

Patients who have lost their nipple-areolar complex (NAC) due to cancer excision surgery or trauma, or who have a congenital absence of the NAC, can experience psychological distress. Therefore, NAC reconstruction procedures have both physical and psychological impacts.

Breast reconstruction is usually performed in multiple stages.

Received: Jul 5, 2016 Revised: Aug 28, 2016 Accepted: Sep 6, 2016 Correspondence: Hyun Gon Choi Department of Plastic and Reconstructive Surgery, Konkuk University Medical Center, Konkuk University School of Medicine, 120-1, Neungdong-ro, Gwangjin-gu, Seoul 05030, Korea. E-mail: 20040059@kuh.ac.kr

Copyright () 2016 The Korean Society for Aesthetic Plastic Surgery.

This is an Open Access article distributed under the terms of the Creative Commons Attribution Non-Commercial License (http://creativecommons.org/licenses/by-nc/4.0/) which permits unrestricted non-commercial use, distribution, and reproduction in any medium, provided the original work is properly cited. www.e-aaps.org
Since reconstruction of the NAC finalizes breast reconstruction following mastectomy, it is important to perform this final step in a precise and delicate way with an optimal surgical technique. The 2 basic methods of NAC reconstruction are local flaps and composite grafts. The surgical techniques that have been developed for NAC reconstruction include the $\mathrm{C}-\mathrm{V}$ flap, the star flap, the skate flap, the bell flap, and the arrow flap [1-7]. Local flaps are preferred because donor site morbidity is minimal compared to composite grafts. The $\mathrm{C}-\mathrm{V}$ flap is a simple, quick, and effective method for nipple reconstruction using a local flap [8].

In these surgical procedures, nipple creation and areola pigmentation are critical [9]. Successful and complete procedures for nipple reconstruction must be simple, reliable, and convenient, with good aesthetic outcomes. The scar-based modified C-V flap technique described in this study is based on the conventional C-V flap technique. The $\mathrm{C}-\mathrm{V}$ flap is a simple method using a local flap, and can be performed in the outpatient department [9]. Of note, the scar-based modified C-V flap can be performed for nipple recon- 
struction and scar revision simultaneously.

This paper describes the scar-based modified C-V flap technique for nipple reconstruction, as well as our experiences with this technique.

\section{METHODS}

A total of 21 patients who underwent nipple reconstruction using the scar-based modified C-V flap technique following unilateral breast reconstruction in our institution from March 2013 to February 2016 were included in this study. All patients underwent mastectomy due to breast cancer, and the NAC was excised because the cancerous mass was located close to a nipple. An implant or tissue expander was inserted under the pectoralis major muscle in the breast reconstruction procedure and acellular dermal matrix was fixed at the lateral margin of the pectoralis major muscle to conceal the implant or expander. Normal saline $(50 \mathrm{cc})$ was injected into the tissue expander every month until the volume became similar to the healthy contralateral side. The sizes of the reconstructed nipples and the normal contralateral nipples were measured with a caliper, focusing on the degree of projection and the diameter before surgery and 3 months after surgery. The nipple volume was calculated. Reduced height of the reconstructed nipple was considered to be projection loss. Statistical analysis was performed using the Wilcoxon signed-rank test. All P-values of less than 0.05 were considered to indicate statistical significance.

\section{Surgical technique}

Nipple reconstruction was performed under local anesthesia using a 1:100,000 dilution of epinephrine. The NAC was excised, so the procedure was always designed on the scar where the mastectomy was performed. The markings for the appropriate positioning of the NAC were drawn on the scar. Nipple width was designed with reference to the contralateral nipple shape, and patients were actively involved in decision-making about the nipple location and width. First, we designed a C flap with an appropriate width and marked it with an "X." Then, outlines including all scar formations were drawn along the scar margins to perform scar revision (Fig. 1A). The C flap was elevated through the level of the subdermal layer while maintaining the pedicle to match the width of the con-
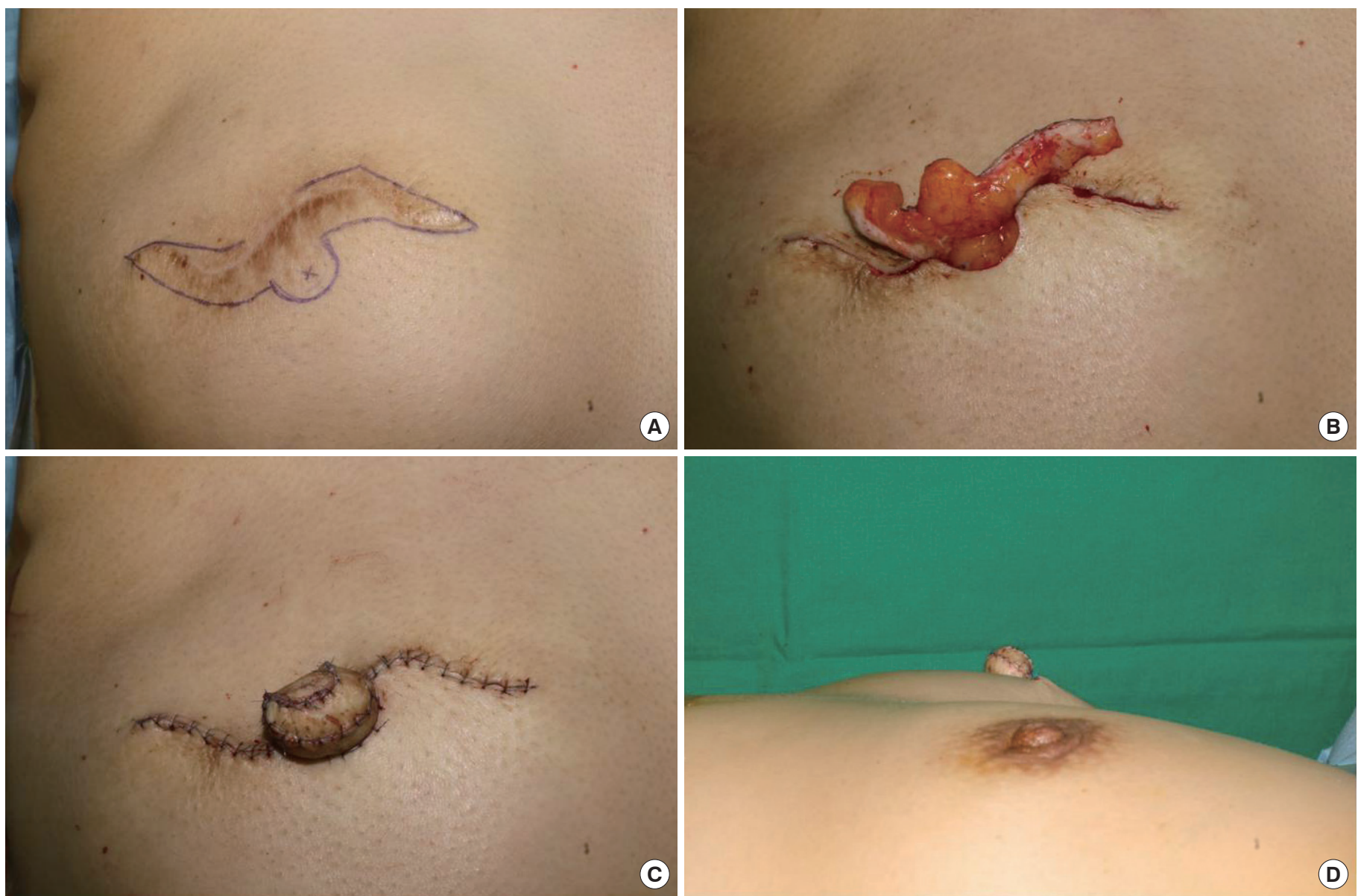

Fig. 1. Surgical technique of the scar-based modified C-V flap described in this study. (A) Design of the scar-based modified C-V flap. (B) Flap elevation and donor site closure. (C) Immediate postoperative appearance of the reconstructed nipple. (D) Lateral view. 
tralateral nipple (Fig. 1B). The donor site was closed primarily using 5-0 absorbable monofilaments for subcutaneous interrupted sutures and 6-0 nylon for the skin interrupted sutures. The V flaps were usually long and asymmetric, allowing the flap to shaped in a way that allowed wrapping with better vascularization. We partially removed the subdermal fat and mainly used the subcutaneous layer. The flap pedicle was centrally located. The V flap was then sutured, wrapping the pedicle to create the proper shape and volume. We considered excising the poorly vascularized distal part of the flap. The flap was sutured with 6-0 simple interrupted nylon (Fig. 1C and 1D).

\section{RESULTS}

All procedures were performed in an outpatient clinic, and the majority of patients underwent implant-based reconstruction. The patients ranged in age from 35 to 62 years at the time of nipple reconstruction, with an average age of 48.4 years. Sixteen patients (76.2\%) underwent primary breast reconstruction with implant insertion. Four patients (19.0\%) underwent secondary breast reconstruction after tissue expander insertion because the area of the excision was too wide for primary closure. One patient underwent breast reconstruction using a latissimus dorsi muscle pedicled flap. Six patients (28.6\%) received adjuvant chemotherapy and one patient $(4.8 \%)$ received radiation therapy. The average interval from breast reconstruction surgery with implant insertion to nipple re-

Table 1. Clinical data of the patients

\begin{tabular}{lc}
\hline & $\mathrm{n}$ (range) /\% \\
\hline Age lyear) & $48.4(35-62)$ \\
Breast reconstruction & $16 / 76.2$ \\
$\quad$ Primary implant insertion & $4 / 19.0$ \\
$\quad \begin{array}{l}\text { Secondary implant insertion after tissue expander } \\
\quad \text { application }\end{array}$ & $1 / 4.8$ \\
Latissimus dorsi muscle pedicled flap & $6 / 28.6$ \\
Adjuvant chemotherapy & $1 / 4.8$ \\
Radiation therapy & $240.6(28-665)$ \\
Length of follow-up (day) & $293.2(150-679)$ \\
Interval from breast reconstruction to nipple & \\
$\quad$ reconstruction (day) &
\end{tabular}

Table 2. Complications in patients

\begin{tabular}{lc}
\hline Complications & $\mathrm{n}(\%)$ \\
\hline Projection loss & $2(9.5)$ \\
Nipple necrosis & $1(4.8)$ \\
Wound infection & $1(4.8)$ \\
Wound dehiscence & $1(4.8)$ \\
Total & 5 complications in 4 patients (19.0) \\
\hline
\end{tabular}

construction was 9.1 months (range, 150-679 days). The average length of the postoperative follow-up period was 7.9 months (240.6 days) (Table 1).

Complications following the scar-based modified C-V flap technique occurred in 5 cases (19.0\%) in 4 patients. These complications comprised projection loss in 2 cases, tip necrosis in 1 case, postoperative infection in 1 case, and wound dehiscence in 1 case (Table 2).

Two patients were lost to follow-up. The average opposite nipple height of the remaining cases was $5.76 \pm 1.30 \mathrm{~mm}$. The immediate postoperative nipple projection height was $6.82 \pm 1.29 \mathrm{~mm}$. Three months after surgery, the average height of the reconstructed nipple projection was $5.71 \pm 1.31 \mathrm{~mm}$. The average size of the opposite nipple diameter was $11.94 \pm 0.97 \mathrm{~mm}$, compared with $12.35 \pm 0.93$ $\mathrm{mm}$ for the diameter of the immediately reconstructed nipples. Three months after surgery, the average reconstructed nipple diameter was $12.94 \pm 1.43 \mathrm{~mm}$ (Fig. 2). The average volumes of the immediately reconstructed nipple and the opposite nipple were $833.58 \mathrm{~mm}^{3}$ and $662.23 \mathrm{~mm}^{3}$, respectively. The average nipple volume at the final visit was $756.75 \mathrm{~mm}^{3}$ (Fig. 3, Table 3).

The newly created nipples maintained their shape and size in 17 cases without loss during the follow-up period. Nipple traction surgery was performed in 2 cases due to projection loss. Local flap cov-

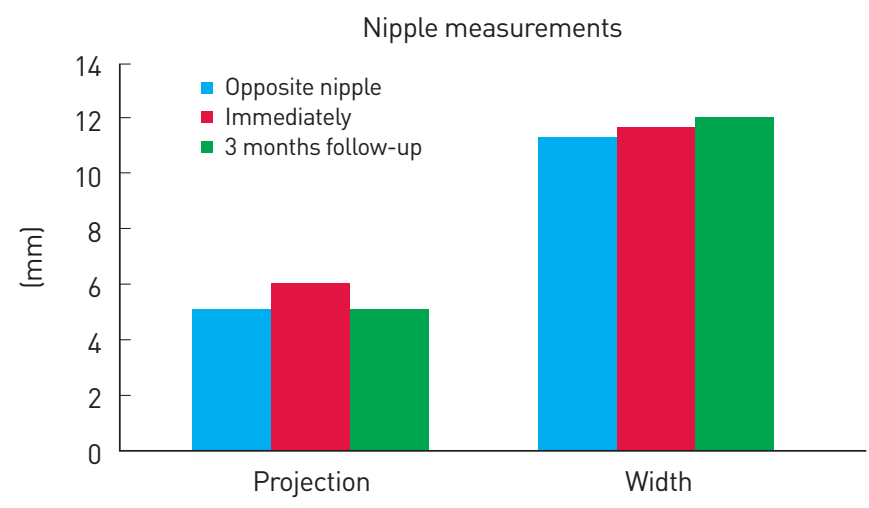

Fig. 2. Nipple measurements.

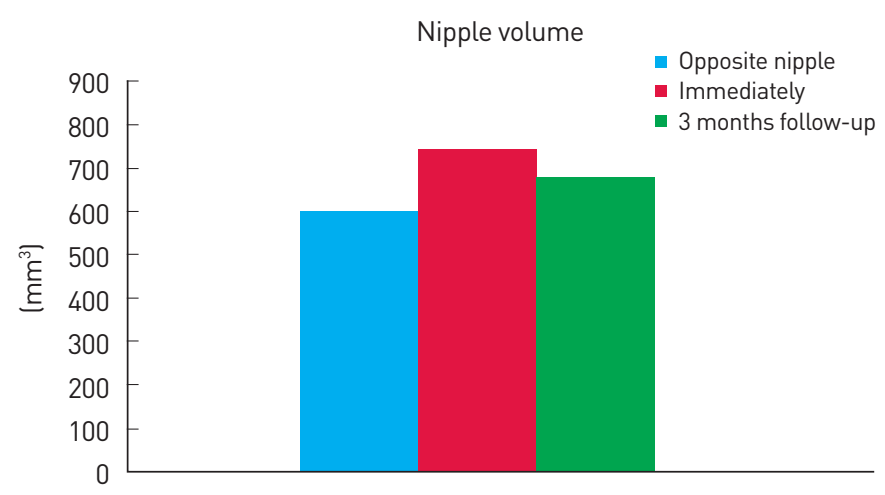

Fig. 3. Nipple volume. 
erage was carried out in the 2 cases of partial flap loss and wound dehiscence. These complications occurred in follow-up visits that

Table 3. Nipple measurements

\begin{tabular}{|c|c|c|c|c|}
\hline & & Average & Difference & P-value \\
\hline \multirow{3}{*}{$\begin{array}{l}\text { Projection } \\
(\mathrm{mm})\end{array}$} & Opposite nipple & 5.76 & - & - \\
\hline & Immediately after surgery & 6.82 & $18.37 \%$ & \\
\hline & At follow-up & 5.71 & $-16.38 \%$ & 0.005 \\
\hline \multirow[t]{3}{*}{ Width (mm) } & Opposite nipple & 11.94 & - & \\
\hline & Immediately after surgery & 12.35 & $3.45 \%$ & \\
\hline & At follow-up & 12.94 & $4.76 \%$ & 0.001 \\
\hline \multirow[t]{3}{*}{ Volume $\left(\mathrm{mm}^{3}\right)$} & Opposite nipple & 662.23 & - & - \\
\hline & Immediately after surgery & 833.58 & $25.88 \%$ & \\
\hline & At follow-up & 756.75 & $-9.22 \%$ & 0.08 \\
\hline
\end{tabular}

took place 32 days and 28 days after the operations, respectively.

\section{Case}

A 48-year-old female underwent a right mastectomy due to ductal carcinoma in situ. Breast reconstruction was performed using a tissue expander. She underwent secondary breast reconstruction with an implant insertion covered with acellular dermal matrix 6 months later (Fig. 4). Seven months after the procedure, the patient underwent nipple reconstruction using the scar-based modified C-V flap technique. The projection and width were $9 \mathrm{~mm}$ and $12 \mathrm{~mm}$, respectively. For the opposite nipple, the projection and width were 8 $\mathrm{mm}$ and $12 \mathrm{~mm}$, respectively (Fig. 5). After 3 months, the projection and width of the reconstructed nipple were $6 \mathrm{~mm}$ and $14 \mathrm{~mm}$, respectively (Fig. 6).
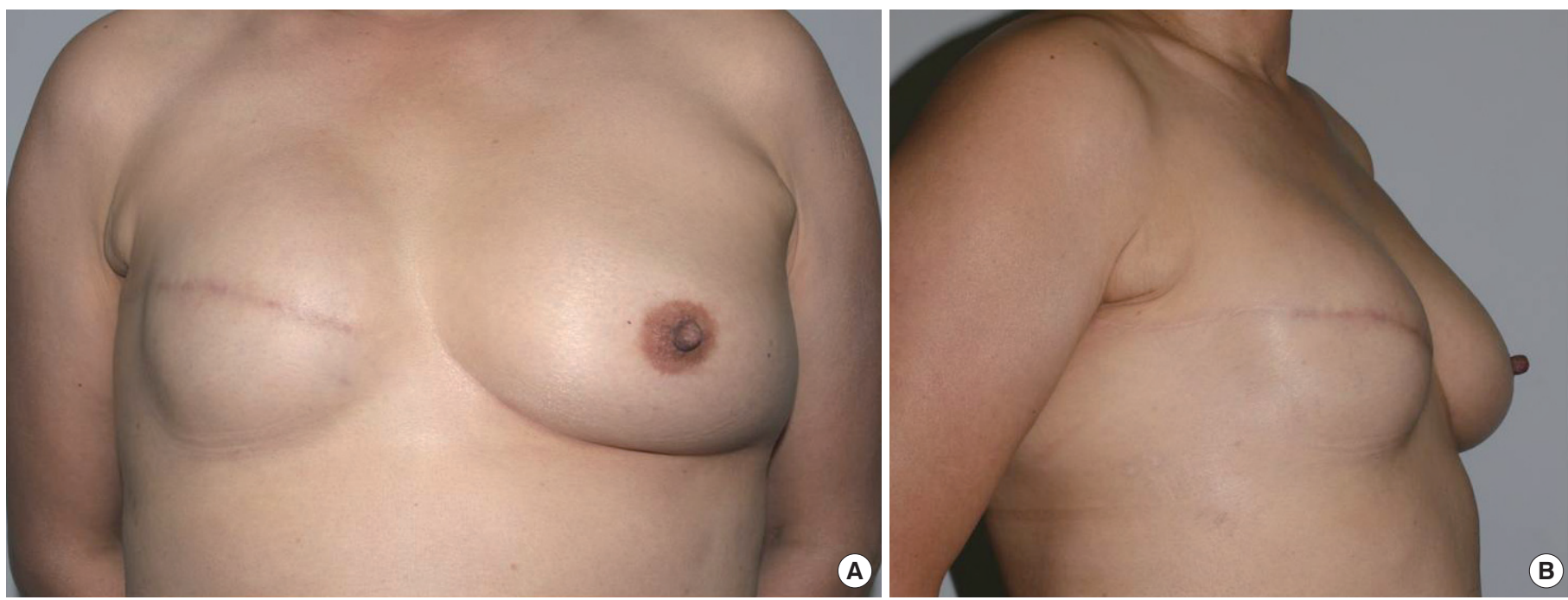

Fig. 4. A 48-year-old woman with ductal carcinoma in situ who underwent 2-stage expander/implant reconstruction following excision of the nipple-areolar complex during a mastectomy. (A) Anteroposterior view. (B) Oblique view.
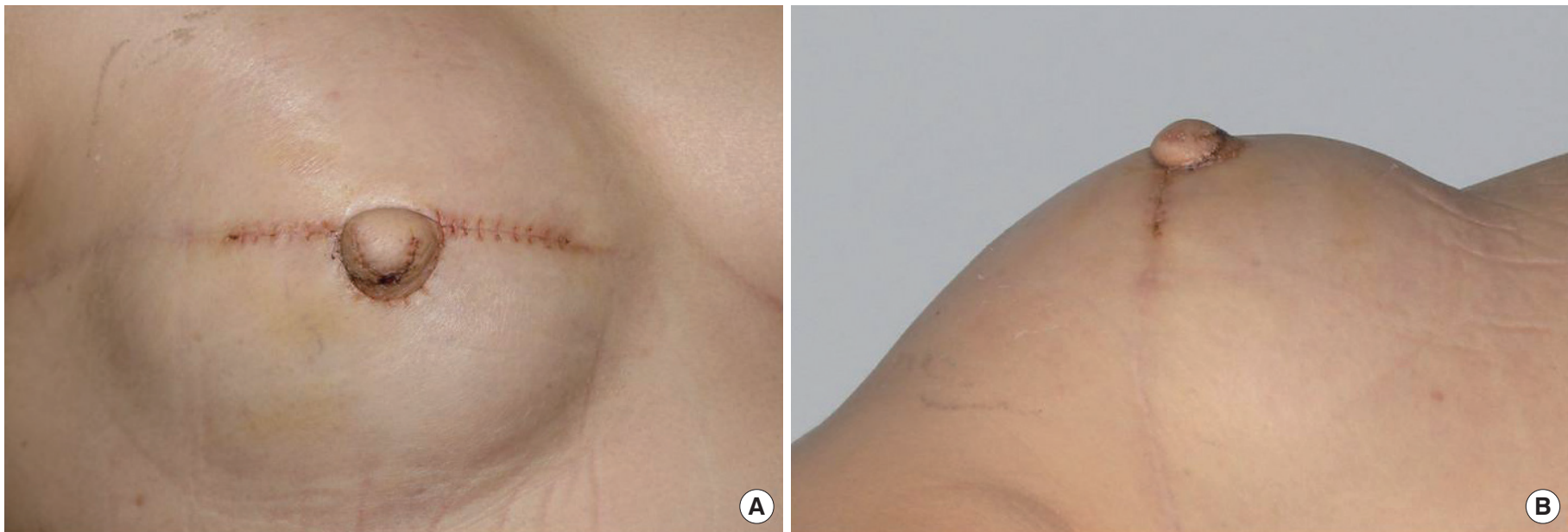

Fig. 5. Postoperative 17 days image of nipple reconstruction. (A) A-P view. (B) Lateral view. 

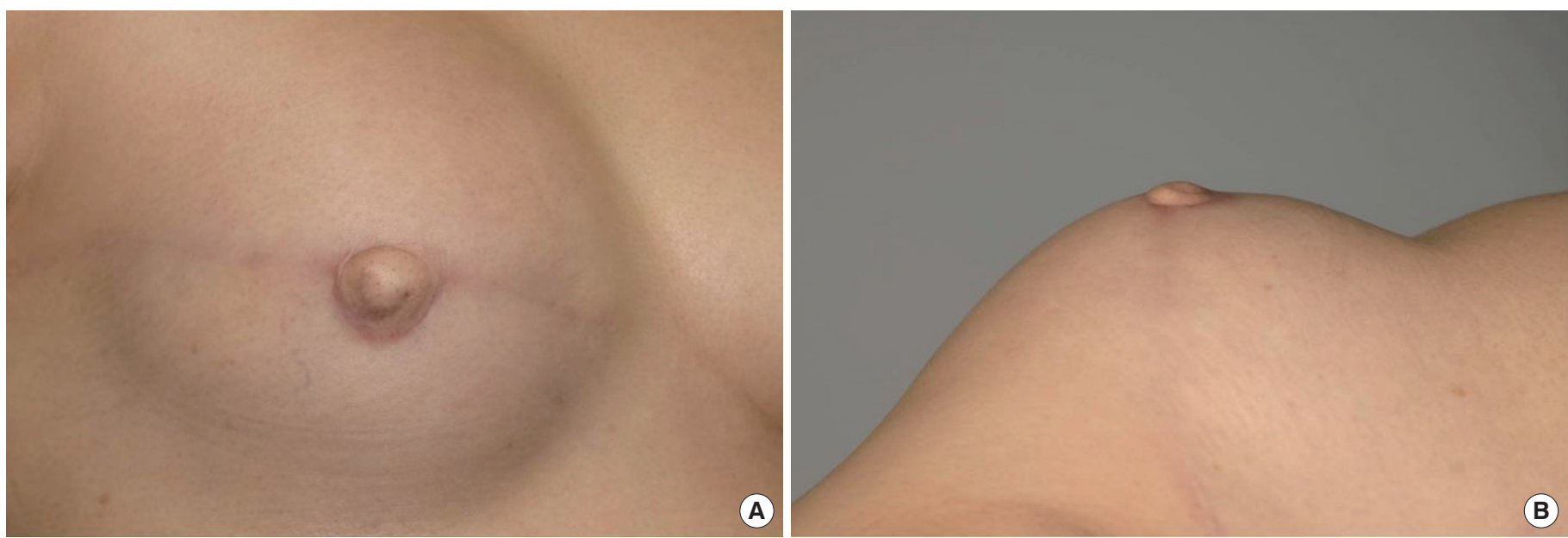

Fig. 6. Postoperative image at 4 months follow up. (A) A-P view. (B) Lateral view.

\section{DISCUSSION}

Reconstruction of the NAC complex is an important part of breast reconstruction following mastectomy, with considerable physical and psychological importance. Although various methods have been described in numerous studies, local flaps and composite grafts remain the basic methods. The design of the $\mathrm{C}-\mathrm{V}$ flap is similar to that of the previously described star flap. The modifications consist of a base, cap, and 2 wings [10]. Following its development in 1998, the $\mathrm{C}-\mathrm{V}$ flap has become standard in numerous procedures due to its long-term satisfaction and improvements in body contour $[9,11$, 12]. This paper reports a modified $\mathrm{C}-\mathrm{V}$ flap technique that uses the post-mastectomy scar.

The loss of projection and volume in the reconstructed nipple is a common disadvantage of the majority of techniques proposed so far. The loss can be as much as $40 \%$ to $60 \%$ [9]. The skate flap and $\mathrm{C}-\mathrm{V}$ flap have an average loss of $30 \%$ to $50 \%$ of nipple projection within one year $[13,14]$. The loss of nipple projection likely occurs in the initial 2 months after reconstruction surgery and stabilizes thereafter [15]. All cases in this study except 2 were followed up for over 3 months. No excessive loss in nipple projection was evident. Comparing the immediate postoperative nipple to the results 3 months after surgery, a $16.3 \%$ loss of projection was observed. The diameter of the reconstructed nipple 3 months after surgery was $4.8 \%$ greater than that of the immediate postoperative nipple. The difference between the volume of the immediate postoperative nipple and the volume measured during the final visit was not significant $(\mathrm{P}=0.08$; Table 3). Projection loss was correlated with a greater diameter, so no significant net effect on volume loss took place. In addition, the degree of loss in the flap tissue was minimized because this technique involved the scar tissue.

Most nipple reconstruction techniques result in a loss of projection, mainly due to fat resorption [16-19] This modified C-V flap technique using scar tissue as the flap provides more projection. The partial removal of subdermal fat while preserving the subdermal plexus might enable the inclusion of minimal subdermal fat within the flap, which may minimize fat resorption. In this study, 2 cases (9.5\%) exhibited projection loss. Satteson et al. [20] reviewed the literature and reported a complication rate of $10.3 \%$, which included projection loss, nipple necrosis, wound infection, and wound dehiscence. We experienced a complication rate of $19.0 \%(n=4)$, with similar complications. We performed additional nipple traction operations in patients due to projection loss. We attribute the projection loss in these 2 cases to the early wearing of a bra, which resulted in breast compression after surgery. Another possible explanation is resorption of the remaining subdermal fat. Local flap coverage was performed for 2 patients due to wound dehiscence and partial nipple necrosis. One patient showed signs of infection that resolved within 2 weeks of postoperative IV antibiotics.

The most popular and widely used techniques in nipple reconstruction are based on a single pedicle, including the $\mathrm{C}-\mathrm{V}$ flap developed by Jones and Bostwick [21], the skate flap developed by Little [22], the star flap developed by Anton et al. [10], and the arrow flap [23]. In order to create a nipple in the procedure described in this study, we modified the $\mathrm{C}-\mathrm{V}$ flap using scar tissue produced by NAC excision. Therefore, we were able to perform scar revision operations simultaneously with nipple reconstruction. The advantage of this technique is that it does not result in new scars and it resolves existing scars. All patients were satisfied with this aspect of the procedure, leading to better compliance and good outcomes.

Local flap techniques have evolved over the past decades to minimize donor morbidity by simplifying the flap design and improving the blood supply [24]. The primary blood supply to the breast skin originates from the subdermal plexus. The volume of the reconstructed nipples created using this technique, which incorporated the scar from the previous NAC excision performed during 
mastectomy, was sufficient for nipple creation. Therefore, we were able to obtain the amount of dermis required for the flap without harvesting excess subdermal fat tissue. Moreover, this procedure makes it easy to build appropriate nipple shapes. Even though we were concerned about inappropriate blood circulation in the scar tissue when we implemented this technique, only 2 cases of partial flap loss (10\%) occurred, because we performed nipple reconstruction a sufficient time after mastectomy. In the meantime, we were able to address concerns about circulation in the newly created nipple because the selective V flap component usually has good vascularity. The circulation within the scar tissue could be considered as good as that of normal tissue after sufficient time for scar formation and remodeling.

The scar-based modified C-V flap technique has several advantages. First, this technique does not result in an additional scar. Instead, incorporates scar revision. Second, since it utilizes the scar located where the nipple was originally located, it is easy to determine the location for nipple reconstruction. Third, since the V flap is relatively long, abundant material is available to create a flap capable of achieving an ideal projection. Fourth, since the flap includes the scar tissue, projection loss is not significant. Finally, it leads to few cases of flap necrosis.

Progress has been made in NAC reconstruction, although it still presents challenges for surgeons. Numerous techniques have been described, and various surgical techniques are available, with no clear consensus regarding the optimal choice. This scar-based C-V flap technique makes it easy to design the flap, and it can be performed conveniently. This modified scar-based $\mathrm{C}-\mathrm{V}$ flap technique is simple and reliable, with good aesthetic outcomes. Therefore, we recommend the scar-based modified C-V flap for nipple reconstruction

The limitations of this study include relatively low reliability regarding our results due to the small number of cases and short follow-up period. Therefore, further studies including more cases are needed. We calculated the volume of the nipple using only diameter and height, which may have been inaccurate. A better method for the exact evaluation of nipple volume is needed. Finally, no satisfactory physiologic and histologic explanation has been proposed for the finding that the projection loss evaluated in this study was not remarkably different from that observed in previous studies, although we used scar tissue, which is generally considered to have worse blood circulation than normal tissue. Further studies of reconstruction using scar tissue are needed.

\section{PATIENT CONSENT}

Patients provided written consent for the use of their images.

\section{REFERENCES}

1. Little JW 3rd. Nipple-areola reconstruction. Clin Plast Surg 1984;11:
$351-64$

2. Hartrampf CR Jr, Culbertson JH. A dermal-fat flap for nipple reconstruction. Plast Reconstr Surg 1984;73:982-6.

3. Kroll SS, Hamilton S. Nipple reconstruction with the double-opposing-tab flap. Plast Reconstr Surg 1989;84:520-5.

4. Thomas SV, Gellis MB, Pool R. Nipple reconstruction with a new local tissue flap. Plast Reconstr Surg 1996;97:1053-6.

5. Eskenazi L. A one-stage nipple reconstruction with the "modified star" flap and immediate tattoo: a review of 100 cases. Plast Reconstr Surg 1993;92:671-80.

6. Hugo NE, Sultan MR, Hardy SP. Nipple-areola reconstruction with intradermal tattoo and double-opposing pennant flaps. Ann Plast Surg 1993;30:510-3.

7. Lossing C, Brongo S, Holmström H. Nipple reconstruction with a modified S-flap technique. Scand J Plast Reconstr Surg Hand Surg 1998;32: 275-9.

8. Losken A, Mackay GJ, Bostwick J 3rd. Nipple reconstruction using the C-V flap technique: a long-term evaluation. Plast Reconstr Surg 2001; 108:361-9.

9. Jabor MA, Shayani P, Collins DR Jr, et al. Nipple-areola reconstruction: satisfaction and clinical determinants. Plast Reconstr Surg 2002; 110:457-63.

10. Anton M, Eskenazi LB, Hartrampf CR. Nipple reconstruction with local flaps: star and wrap around flaps. Perspect Plast Surg 1991;5:67-78.

11. Valdatta L, Montemurro P, Tamborini F, et al. Our experience of nipple reconstruction using the C-V flap technique: 1 year evaluation. J Plast Reconstr Aesthet Surg 2009;62:1293-8.

12. El-Ali K, Dalal M, Kat CC. Modified C-V flap for nipple reconstruction: our results in 50 patients. J Plast Reconstr Aesthet Surg 2009;62: 991-6.

13. Katsuragi Y, Kayano S, Koizumi T, et al. How long does the nipple projection last after reconstruction using the skate flap purse-string technique? Plast Reconstr Surg 2011;127:149e-51e.

14. Otterburn DM, Sikora KE, Losken A. An outcome evaluation following postmastectomy nipple reconstruction using the C-V flap technique. Ann Plast Surg 2010;64:574-8.

15. Few JW, Marcus JR, Casas LA, et al. Long-term predictable nipple projection following reconstruction. Plast Reconstr Surg 1999;104:1321-4.

16. Vendemia N, Mesbahi AN, McCarthy CM, et al. Nipple areola reconstruction. Cancer J 2008;14:253-7.

17. Schubert HM, Schoeller T, Wechselberger G. Nipple reconstruction using a modified arrow flap technique. J Plast Reconstr Aesthet Surg 2009;62:115-6.

18. Turgut G, Sacak B, Görgülü T, et al. Nipple reconstruction with bipedicled dermal flap: a new and easy technique. Aesthetic Plast Surg 2009; 33:770-3.

19. Dolmans GH, van de Kar AL, van Rappard JH, et al. Nipple reconstruction: the "Hammond" flap. Plast Reconstr Surg 2008;121:353-4.

20. Satteson ES, Reynolds MF, Bond AM, et al. An analysis of complication risk factors in 641 nipple reconstructions. Breast J 2016;22:379- 
83.

21. Jones G, Bostwick J. Nipple-areolar reconstruction. Oper Tecch in Plast Reconstr Surg 1994;1:35-8.

22. Little JW. Nipple-areolar reconstruction. In: Cohen M, Goldwyn RM, editors. Mastery of plastic and reconstructive surgery. Boston, MA: Little, Brown; 1994. p.1342-8.
23. Guerra AB, Khoobehi K, Metzinger SE, et al. New technique for nipple areola reconstruction: arrow flap and rib cartilage graft for longlasting nipple projection. Ann Plast Surg 2003;50:31-7.

24. Farhadi J, Maksvytyte GK, Schaefer DJ, et al. Reconstruction of the nipple-areola complex: an update. J Plast Reconstr Aesthet Surg 2006; 59:40-53. 